\title{
Association of cognitive judgment and shyness with frequency and quality of flow experience
}

\author{
This article was published in the following Dove Press journal: \\ Psychology Research and Behavior Management \\ 7 November 2012 \\ Number of times this article has been viewed
}

\section{Kazuki Hirao \\ Ryuji Kobayashi \\ Kenji Yabuwaki}

Department of Occupational Therapy, School of Health Science and Social Welfare, Kibi International University, Takahashi City, Okayama, Japan
Correspondence: Kazuki Hirao

8 Iga-machi, Takahashi City,

Okayama 716-8508, Japan

Tel +8I 866224044

Fax +81 866224044

Email hirao-k@kiui.ac.jp
Objective: To determine the association of cognitive judgment and shyness with frequency and quality of flow experience.

Design and methods: This was a cross-sectional survey of the relationship between psychological tendency and frequency and quality of flow experience in 68 college students, undertaken in Hiroshima, Japan. The predictors were Shyness Scale scores, measure of ambiguity tolerance scores, and Life Orientation Test scores, and the outcome was the frequency and quality of flow experience.

Results: The results of the binary logistic regression analysis indicated that only the measure of ambiguity tolerance $(P=0.02$, odds ratio $=1.06$, and 95\% confidence interval $=1.01-1.11)$ was a predictor of the quality of flow experience, and only the Shyness Scale $(P=0.007$, odds ratio $=0.95$, and $95 \%$ confidence interval $=0.91-0.98$ ) was a predictor of the frequency of flow experience.

Conclusion: The findings suggest that ambiguity tolerance and shyness are associated with the frequency and quality of the flow experience.

Keywords: Flow experience, positive psychology, shyness, ambiguity tolerance, life orientation

\section{Introduction}

One of the core constructs of the positive psychology movement is "flow". ${ }^{1}$ Flow has been defined as "the holistic sensation that people feel when they act with total involvement." 2 According to Csikszentmihalyi, flow is also "the state in which people are so involved in an activity that nothing else seems to matter; the experience itself is so enjoyable that people will do it even at great cost, for the sheer sake of doing it."3 There is substantial evidence suggesting that the flow experience is associated with subjective stress and health-related quality of life (QOL). ${ }^{4-6}$ Therefore, to help improve people's QOL, it is important to understand the psychological tendencies associated with the flow experience.

Numerous studies have suggested a relationship between flow and psychological tendencies. For example, a study that examined the relationship between the Big Five personality traits and the flow experience suggested that extraversion and openness affected the frequency of the flow experience, openness enhanced its strength, and neuroticism had a restraining influence on it. ${ }^{7}$ This finding is important as it helps us to understand the psychological tendencies that are loosely associated with the flow experience. However, to understand this in detail, it is necessary to clarify the relationship between flow experience and psychological tendencies such as shyness and cognitive judgment (ie, self-feeling optimistic and ambiguity tolerance) because 
these are frequently experienced psychological tendencies in daily life.

In the research reported here, we sought to determine the association of cognitive judgment and shyness with the frequency and quality of flow experience.

It is believed that psychological tendencies, which predict the frequency and quality of flow experience, can contribute to the improvement of QOL.

\section{Methods Study design}

A cross-sectional study of the relationship between psychological tendency and the frequency and quality of flow experience was conducted in September 2010 in Japan.

\section{Participants}

The survey study population was a convenience sample of healthy college students ( $\mathrm{N}=68$ : 44 male and 24 female) in Hiroshima, Japan. All participants provided their written informed consent and were assured of their anonymity.

\section{Data collection}

The participants gathered in a lecture room and questionnaires were distributed to them. The authors explained the questionnaires in detail to the participants. The questionnaires were immediately collected once the participants had completed them. This survey was conducted after a regular kinesiology lecture.

\section{Measures}

\section{Flow Experience Checklist}

This checklist, a convenient means of measuring the frequency and quality of flow in daily life, consists of one item that assesses the frequency of flow experience in daily life and ten items for the quality of flow experience. These items were measured on a seven-point scale (1 = very strongly disagree; 7 = very strongly agree). The reliability and validity of this scale have been previously confirmed. ${ }^{7}$

\section{Life Orientation Test (LOT)}

This scale, which was developed by Scheier and Carver, ${ }^{8}$ was translated into Japanese by Nakamura. ${ }^{9}$ It consists of two factors: self-feeling optimistic and self-feeling pessimistic. It comprises three items for the former and four for the latter, which were measured on a five-point scale. A high self-feeling optimistic score indicates a greater tendency toward optimism while a high self-feeling pessimistic score indicates a greater tendency toward pessimism. The reliability and validity of this scale have been confirmed previously. ${ }^{9}$

\section{Shyness Scale (Japanese version)}

The Shyness Scale, developed by Sakurai and Sakurai, ${ }^{10}$ is a Japanese translation of the Social Reticence Scale developed by Jones and Russell. ${ }^{11}$ The scale consists of 19 items measured on a five-point scale ( 1 = strongly inapplicable; $5=$ strongly applicable). According to this scale, the higher the score, the higher the tendency towards shyness. The reliability and validity of this scale have been confirmed previously. ${ }^{10}$

\section{Psychological health-related measure of ambiguity tolerance (MAT)}

This scale is based on Norton's MAT-50, ${ }^{12}$ which focuses on mental stress. ${ }^{13}$ It consists of 24 items measured on a five-point scale with anchoring values of 1 (positive) and 5 (negative). A high score on this scale indicates a high level of tolerance, meaning that an ambiguous situation can be endured. The reliability and validity of this scale have been confirmed previously. ${ }^{13}$

\section{Data analysis}

Descriptive statistics were calculated for each variable. We employed binary logistic regression analysis with the forward selection method to allow the calculation of adjusted odds ratios (ORs) and 95\% confidence intervals (CIs). The Hosmer-Lemeshow goodness-of-fit statistic was $P>0.05$ in all cases. ${ }^{14}$ Logistic regression analysis was used to examine the association between self-feeling optimistic, self-feeling pessimistic, shyness, MAT, and the frequency and quality of flow experience. We divided the two values into high-score and low-score groups on the basis of the average scores obtained from the Flow Experience Checklist (frequency and quality of flow experience). These were used as the dependent variables in the analysis. Independent variables included age, sex, self-feeling optimistic, self-feeling pessimistic, shyness, and MAT. All ORs were adjusted for age and sex. The results are shown as the mean \pm standard deviation (SD). All tests were two-tailed; a $P$ value of $<0.05$ was accepted as indicating statistical significance. A personal computer with Statistical Package for the Social Sciences (SPSS) software for Windows (v 19; IBM Corp, Armonk, NY) was employed for all analyses.

\section{Results}

Table 1 shows the characteristics of participants and the values for each scale. The mean age of the participants in the 
Table I Participants' characteristics

\begin{tabular}{ll}
\hline Variable & Mean \pm SD or number \\
\hline Age (years) & $22.6 \pm 4.6$ \\
Male/female $(\mathrm{n})$ & $44 / 24$ \\
Flow Experience Checklist & \\
Frequency of flow experience & $4.5 \pm 1.4 \mathrm{I}$ \\
Quality of flow experience & $48.54 \pm 10.5$ \\
Life Orientation Test & \\
Self-feeling optimistic & $8.97 \pm 2.44$ \\
Self-feeling pessimistic & $12.09 \pm 2.95$ \\
Shyness Scale & $53.6 \pm 14.78$ \\
Measure of ambiguity tolerance & $69.31 \pm 11.23$ \\
\hline
\end{tabular}

Abbreviation: SD, standard deviation.

sample was 22.6 years $(\mathrm{SD}=4.6)$. The mean for the Flow Experience Checklist was $4.51 \pm 1.41$ for frequency of flow experience and $48.54 \pm 10.5$ for quality of flow experience. For LOT, it was $8.97 \pm 2.44$ for self-feeling optimistic and $12.09 \pm 2.95$ for self-feeling pessimistic. The mean for the Shyness Scale was $53.6 \pm 14.78$ and $69.31 \pm 11.23$ for the MAT.

\section{Predictors for quality of flow experience}

The quality of flow experience was 29 for the low-score group and 39 for the high-score group.

In the logistic regression analysis, only the MAT $(P=0.02$, $\mathrm{OR}=1.06,95 \% \mathrm{CI}=1.01-1.11)$ was a predictor of quality of flow experience (Table 2). The LOT was not significantly associated with the quality of flow experience.

\section{Predictors for frequency of flow experience}

The frequency of flow experience was 25 for the low-score group and 43 for the high-score group.

In the logistic regression analysis, only the Shyness Scale $(P=0.007, \mathrm{OR}=0.95$, and $95 \% \mathrm{CI}=0.91-0.98)$ was a predictor of the frequency of flow experience (Table 2). The LOT was not significantly associated with the frequency of flow experience.

Table 2 Logistic regression analysis of predictors for "quality" and "frequency" of flow experience

\begin{tabular}{|c|c|c|c|}
\hline Variable & Odds ratio & $\begin{array}{l}95 \% \text { confidence } \\
\text { interval }\end{array}$ & $P$ value \\
\hline \multicolumn{4}{|c|}{ Quality of flow experience } \\
\hline $\begin{array}{l}\text { Measure of ambiguity } \\
\text { tolerance }\end{array}$ & 1.06 & $1.01-1.11$ & 0.02 \\
\hline \multicolumn{4}{|c|}{ Frequency of flow experience } \\
\hline Shyness Scale & 0.95 & $0.91-0.98$ & 0.007 \\
\hline
\end{tabular}

\section{Discussion}

The results of the analyses suggest that ambiguity tolerance is associated with the quality of flow experience, and that shyness is negatively associated with the frequency of flow experience.

Ambiguous stimuli and information are generally considered unpleasant. When information is vague, an accurate prediction of the situation becomes difficult, and it becomes difficult to control the inconvenient situation. ${ }^{13}$ A previous study has suggested that a dislike for working in a group correlates negatively with tolerance for disagreement, ambiguity, and argumentativeness. ${ }^{15}$ In the present study, ambiguity tolerance was associated with the quality of flow experience.

Since there was a positive effect on the quality of the flow, it was possible to concentrate on the problem, if not distracted by the idle thoughts surrounding the ambiguous situation. It has been suggested that shyness negatively affects psychosocial awareness. ${ }^{16-18}$ In addition, shyness was found to have a negative impact on the frequency of flow experience in the present study. Therefore, the authors contend that it is possible that lack of confidence can prevent one from reaching the flow state, resulting in a problem. Flow is experienced when a high-level challenge is balanced by high-level skills and intrinsic rewards are generated. Therefore, in the case of lacking confidence, to reach the flow state, the level of a challenge must be reduced or the ability to accomplish a task must be improved.

The nonsignificant association of the LOT with the frequency and quality of flow experience was an unexpected result. A previous study has suggested "that the effective integration and regulation of emotional and autobiographical information supports the projection of positive future events in healthy individuals, and is related to optimism." ${ }^{19}$ Optimism is a feeling about the future, whereas the flow is a feeling about the present. Thus, there may not be a direct relationship between them. This issue should be studied further in the future.

There are some limitations to this study. Our data are from a cross-sectional study, which limits the attributions about the direction of causality between the variables. Our findings require further examination in longitudinal studies. In addition, our data are from limited areas in Japan, so further examination covering a wider area is required.

\section{Conclusion}

Ambiguity tolerance and shyness have an effect on the frequency and quality of flow experience. This is a new finding and highlights the importance of these psychological tendencies. 


\section{Disclosure}

The authors report no conflicts of interest in this work.

\section{References}

1. Fullagar CJ, Kelloway EK. Flow at work: an experience sampling approach. J Occup Organ Psychol. 2009;82(3):595-615.

2. Csikszentmihalyi M. Beyond Boredom and Anxiety: Experiencing Flow in Work and Play. San Francisco, CA: Jossey-Bass; 1975.

3. Csikszentmihalyi M. Flow: The Psychology of Optimal Experience. New York, NY: Harper and Row; 1990.

4. Hirao K, Kobayashi R, Okishima K, Tomokuni Y. Flow experience and health-related quality of life in community dwelling elderly Japanese. Nurs Health Sci. 2012;14(1):52-57.

5. Hirao K, Kobayashi R, Okishima K, Tomokuni Y, Yabuwaki K. Influence of different intensities of brief flow experiences on subjective and objective stress. Med Biol. 2011;155(10):713-720. Available from http://ci.nii.ac.jp/naid/40019018652. Accessed August 15, 2012.

6. Hirao K, Kobayashi R, Okishima K, Tomokuni Y. Influence of flow experience during daily life on health-related quality of life and salivary amylase activity in Japanese college students. Japanese Journal of Occupational Medicine and Traumatology. 2011;59(1):13-18.

7. Ishimura I. Psychological study on enhancing factors and positive functions of flow experiences [PhD thesis]. Tsukuba: University of Tsukuba; 2008. Japanese.

8. Scheier MF, Carver CS. Optimism, coping, and health: assessment and implications of generalized outcome expectancies. Health Psychol. 1985;4(3):219-247.

9. Nakamura H. Individual Differences of Psychological Characteristics in the Face-To-Face Setting. Tokyo: Brain Shuppan; 2000. Japanese. Available from http://ci.nii.ac.jp/ncid/BA49606137. Accessed August 15,2012 .
10. Sakurai S, Sakurai T. Daigakusei-you shyness syakudo no nihongo-ban no sakusei to datousei no kentou [Construction of Japanese version of Shyness Scale for college students]. Bulletin of Nara University Education. 1991;40(1):235-243. Japanese.

11. Jones WH, Russell D. The Social Reticence Scale: an objective instrument to measure shyness. J Pers Assess. 1982;46(6):629-631.

12. Norton RW. Measurement of ambiguity tolerance. J Pers Assess. 1975; 39(6):607-619.

13. Shinya M. Effects of ambiguity tolerance on the psychological stress process. Bulletin of the Faculty of Education Ibaraki University. 1998;47:151-163. Japanese. Available from http://ci.nii.ac.jp/naid/ 110000108031. 13 Accessed August 15, 2012.

14. Hosmer DW, Lemeshow S. Applied Logistic Regression, 2nd ed. New York, NY: Wiley; 2000.

15. Madlock PE, Kennedy-Lightsey CD, Myers SA. Employees' communication attitudes and dislike for working in a group. Psychol Rep. 2007;101(3 Pt 2):1037-1040.

16. Lee Y, Halberg KJ. An exploratory study of college students' perceptions of freedom in leisure and shyness. Leisure Sci. 1989;11(3):217-227.

17. Goiato MC, Dos Santos DM, Bannwart LC, et al. Psychosocial impact on anophthalmic patients wearing ocular prosthesis. Int J Oral Maxillofac Surg. In press.

18. Erwin PG. The effects of shyness on love styles and relationship status. Psychol Rep. 2007;101(2):670-672.

19. Sharot T, Riccardi AM, Raio CM, Phelps EA. Neural mechanisms mediating optimism bias. Nature. 2007;450(7166):102-105.
Psychology Research and Behavior Management

\section{Publish your work in this journal}

Psychology Research and Behavior Management is an international, peerreviewed, open access journal focusing on the science of psychology and its application in behavior management to develop improved outcomes in the clinical, educational, sports and business arenas. Specific topics covered include: Neuroscience, memory \& decision making; Behavior

\section{Dovepress}

modification \& management; Clinical applications; Business \& sports performance management; Social and developmental studies; Animal studies. The manuscript management system is completely online and includes a quick and fair peer-review system. Visit http://www.dovepress. com/testimonials.php to read real quotes from published authors. 